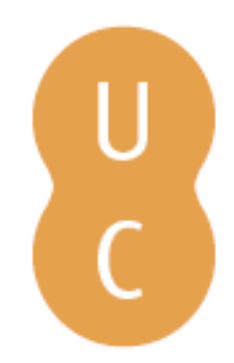

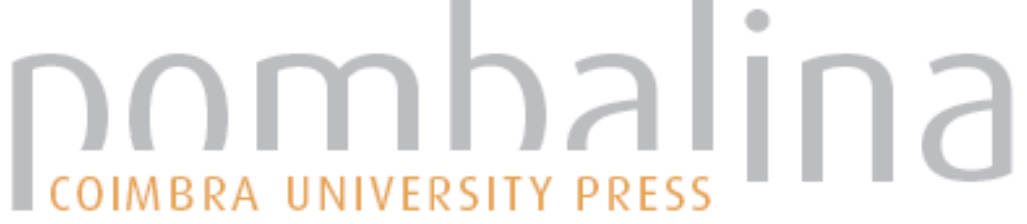

\section{O mar na comédia plautina}
Autor(es):
Couto, Aires Pereira do
Publicado por: Imprensa da Universidade de Coimbra
URL persistente:
URI:http://hdl.handle.net/10316.2/38351
DOI:
DOI:http://dx.doi.org/10.14195/978-989-26-0438-1_11

Accessed : $\quad$ 26-Apr-2023 06:17:17

A navegação consulta e descarregamento dos títulos inseridos nas Bibliotecas Digitais UC Digitalis, UC Pombalina e UC Impactum, pressupõem a aceitação plena e sem reservas dos Termos e Condições de Uso destas Bibliotecas Digitais, disponíveis em https://digitalis.uc.pt/pt-pt/termos.

Conforme exposto nos referidos Termos e Condições de Uso, o descarregamento de títulos de acesso restrito requer uma licença válida de autorização devendo o utilizador aceder ao(s) documento(s) a partir de um endereço de IP da instituição detentora da supramencionada licença.

Ao utilizador é apenas permitido o descarregamento para uso pessoal, pelo que o emprego do(s) título(s) descarregado(s) para outro fim, designadamente comercial, carece de autorização do respetivo autor ou editor da obra.

Na medida em que todas as obras da UC Digitalis se encontram protegidas pelo Código do Direito de Autor e Direitos Conexos e demais legislação aplicável, toda a cópia, parcial ou total, deste documento, nos casos em que é legalmente admitida, deverá conter ou fazer-se acompanhar por este aviso.

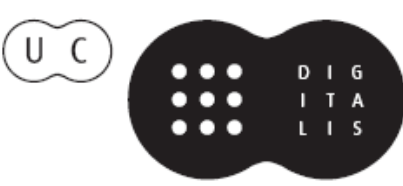


Francisco de Oliveira

Pascal Thiercy

Raquel Vilaça

Coordenação

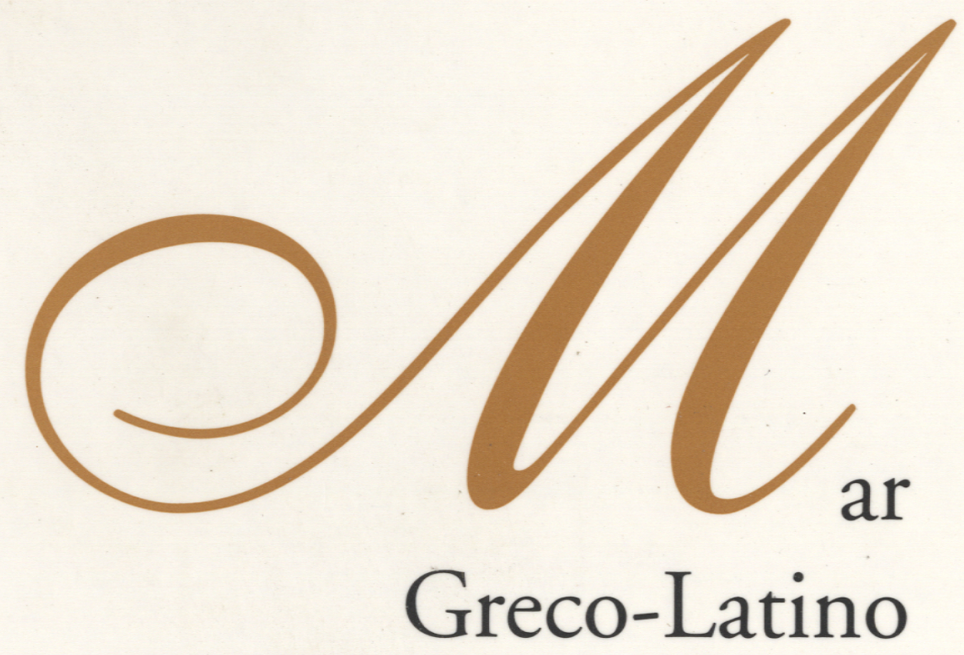

- colmbra 2006 


\title{
O MAR NA COMÉDIA PLAUTINA
}

\author{
Aires Pereira do Couto
}

UCP - Viseu

Na comédia plautina os acontecimentos cénicos são sempre colocados em cidades banhadas pelo mar, como Atenas ${ }^{(1)}$ (a acção de doze das vinte e uma comédias passa-se nesta cidade: Asinaria, Aulularia, Bacchides, Casina, Epidicus, Mercator, Mostellaria, Persa, Pseudolus, Stichus, Trinummus e Truculentus), Epidauro (Curculio), Epidamno (Menaechmi), Éfeso (Miles gloriosus), numa cidade não identificada da Etólia (Captiui), ou em cidades muito próximas do mar, como Sícion (Cistellaria) e Cálidon (Poenulus). Em rigor até Atenas poderia fazer parte do grupo de cidades somente próximas do mar. ${ }^{(2)}$

Duas das comédias de Plauto apresentam mesmo como lugar cénico praias, em vez da habitual cidade. É o que acontece com a Rudens, cuja acção decorre numa praia junto a Cirene, cidade do Norte de África, e com a Vidularia, cuja cena está situada também numa praia, junto à mesma cidade de Cirene, segundo alguns, ou na costa da Ática, junto ao cabo Súnio, segundo outros. ${ }^{(3)}$

\footnotetext{
(1) Segundo uma convenção grega, quando o texto não apresenta qualquer indicação do local, isso significa que o lugar da acção é Atenas.

(2) Cf. C. Questa - R. Raffaelli, "Il naufragio felice - Porti pirati e naufraghi nelle commedie di Plauto" in idem, Maschere Prologhi Naufragi nella commedia plautina, Bari, Adriatica Editrice, $1984,123$.

${ }^{3}$ Cf. Roberto Calderan, Tito Maccio Plauto - Vidularia, Urbino, Quattro Venti, 2004, pp.123-124.
} 
É ainda significativo que a única cidade não marítima em que se situa a acção de uma comédia latina - Tebas, no Amphitruo - acabe por, também ela, possuir um porto, ainda que irreal, naturalmente, por se tratar de uma cidade do interior da Grécia. Apesar disso, não são poucas as referências a este porto feitas ao longo da peça. No v.149, o escravo Sósia é anunciado por Mercúrio como estando a chegar do porto de Tebas; e o próprio Sósia, na sua primeira aparição em cena, diz, nos vv. 162-165, que foi a impaciência do seu amo Anfitrião que, contra a sua vontade, o fez sair do porto em plena noite. Volta a aludir à sua vinda do porto nos vv.195, 404, 602 e 701, e no v.460 diz-nos que vai regressar ao porto para contar ao seu patrão o que se passara à porta de sua casa; e até o enjoo que a viagem de barco lhe provocara, e que ainda sentia, lhe merece um comentário em aparte no v.329. Também Mercúrio, assumindo-se como Sósia, afirma que o barco em que viajara partira naquela noite do porto pérsico (v.412). O próprio Anfitrião se refere várias vezes à sua chegada ao porto de Tebas, depois da viagem por mar desde o porto pérsico, vencida a guerra contra os Teléboas (vv.629, 731-732, 849). Curiosamente, até uma das personagens - Blefarão - nos remete para o mar e para o porto, já que ele é o timoneiro do barco que trouxe Anfitrião da guerra (vv.950 e 967).

A comédia, como todo o teatro antigo, estava sujeito a limitações práticas e a convenções e regras rígidas que condicionavam as representações em cena. ${ }^{(4)}$ A cena da comédia era muito simples: representava, por norma, duas ou três casas ou, em alternativa, uma ou duas casas e um templo; à sua frente tínhamos uma rua ou uma praça pública. De cada um dos lados existia uma saída: a que ficava à direita dos espectadores conduzia habitualmente ao centro da cidade, ao foro; a da esquerda, para fora da cidade,

\footnotetext{
(4) Sobre as técnicas e as convenções cénicas, veja-se F. Dupont, L'acteur-roi ou le thêâtre dans la Rome antique, Paris, Les Belles Lettres, 1985, pp.69-91; e G. E. Duckworth, The nature of Roman comedy. A study in popular entertainment. Second edition with a Foreword and Bibliographical Appendix by Richard Hunter, Oklahoma, 1994, pp.102-138.
} 
para o campo ou para o porto, ponto de chegada ou de partida de personagens várias e porta de entrada de riquezas. ${ }^{(5)}$ Esta convenção cénica é, desde logo, reveladora da importância atribuída ao mar enquanto via de comunicação privilegiada.

Como veremos, as viagens por mar são, em algumas das comédias de Plauto, responsáveis pelos problemas iniciais das histórias e, em muitas delas, a saída que conduz ao porto é a principal via de partida ou chegada de personagens importantes para o desenrolar da acção. O mar surge, portanto, como um lugar privilegiado de mudanças, por vezes inesperadas, que, frequentemente, acabam por provocar viragens importantes, senão mesmo decisivas, no desenrolar da acção. O mar representa o lugar do imprevisto e do inesperado, o espaço através do qual sucedem, amiúde, acontecimentos e mudanças que condicionam a intriga das comédias. ${ }^{(6)}$ É também por via marítima que se verificam, algumas vezes, regressos indesejados, geralmente dos velhos pais, que, após ausências mais ou menos prolongadas, regressam do estrangeiro e vão pôr cobro às vidas folgadas dos filhos.

Mas fixemo-nos nas comédias plautinas e vejamos a importância que o mar assume em algumas delas.

No Amphitruo, é através do porto, ainda que irreal, como já referimos, que chegam à cena, regressando da guerra contra os Teléboas, primeiro o escravo Sósia, na cena I do acto I, e mais tarde o próprio Anfitrião, na cena I do acto II, chegadas responsáveis pelo quiproquó que se vai instalar. Nas Bacchides, a acção propriamente dita começa no momento em que as duas irmãs cortesãs - as Báquides - chegam do porto onde a Báquide II acabara de desembarcar (v.106) ${ }^{(7)}$; é ainda depois de uma viagem por mar que, na cena II do acto III, chega aquele que provocará um grande equívoco, o jovem

\footnotetext{
(5) Cf. F. Dupont, "La rue, lieu unique de la sociabilité dans la comédie romaine" in La rue, lieu de sociabilitée, Actes du Colloque de Rouen, 16-19 novembre 1994, Rouen, Publications de L'Université de Rouen n'214, 1997, pp.43-53.

(6) Cf. C. Questa - R. Raffaelli, op. cit., pp.122-124.

(7) Cf. B. Taladoire, Essai sur le comique de Plaute, Monaco, 1956, p.99.
} 
Mnesíloco, que, vindo de Éfeso - onde tinha sido enviado por seu pai cerca de dois anos antes, para cobrar uma dívida de mil e duzentas moedas de ouro -, regressa a Atenas. Nos Captiui, é do porto que, como diz o parasita Ergásilo, surge a felicidade (v.869); pois, é por via marítima que regressam o ex-prisioneiro Filócrates, trazendo consigo Filopólemo, o filho de Hegião, para o restituir ao velho pai, e também, contra todas as expectativas e esperanças do velho, o escravo fugitivo Estalagmo, que muitos anos antes fugira de casa raptando um outro filho de Hegião com apenas quatro anos de idade. O regresso do escravo Estalagmo vai permitir que, no final da peça, se fique a saber que essa criança não morreu, e, com as revelações feitas, que o velho Hegião reconheça em Tíndaro, o escravo de Filócrates, o filho outrora raptado por Estalagmo (vv.873 sqq.).

São também várias as comédias onde se verifica o regresso, por via marítima, de personagens ausentes durante muito tempo, geralmente os velhos pais. É o que acontece na Mostellaria, onde o velho Teoprópides regressa do Egipto, para onde fora em viagem de negócios. A notícia deste regresso inesperado e indesejado, trazida do porto pelo escravo Tranião (v.366 sqq.), vai pôr fim à vida folgada do seu filho Filólaques e vai provocar uma série de enganos e desenganos antecipados pelo escravo, quando diz: "que enorme montanha de males acabei de ver no porto! O meu amo chegou do estrangeiro" (vv.352-353) ${ }^{(8)}$. O mesmo acontece no Trinummus, onde o velho Cármides regressa de Selêucia, para onde tinha ido de Atenas em viagem de negócios com o intuito de recuperar a fortuna esbanjada pelo filho Lesbonico. O seu regresso apanha todos de surpresa e serve para desmascarar o sicofanta que, enquanto falso mensageiro, fingia trazer da parte de Cármides uma importância em dinheiro e duas cartas para entregar a Lesbonico e ao

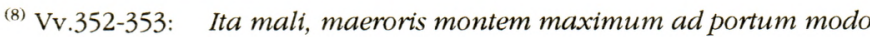
conspicatus sum. Erus aduenit peregre.
}

As citações latinas das comédias de Plauto incluídas nesta comunicação foram feitas a partir da edição estabelecida por A. Ernout (Paris, Les Belles Lettres, 1932-40, 7 vols.). 
seu amigo Cálicles (vv.843 sqq.). Na cena III do acto II do Curculio, o parasita de Fédromo, Gorgulho, regressa a Epidamno por mar, vindo de Cária, onde tinha sido enviado por Fédromo com o objectivo de lhe conseguir um empréstimo para resgatar a sua amada Planésio que se encontrava, na condição de escrava, em casa do alcoviteiro Cápadox. No Epidicus, regressam por mar o jovem Estratípocles, vindo da guerra em Tebas, e Filipa, a mulher que Perífanes seduziu na sua juventude, em Epidauro, e que é a mãe de Teléstis, a moça por quem Estratípocles se apaixonou. Nos Menaechmi, é por mar que Menecmo II, depois de seis anos de buscas, chega a Epidamno na companhia do seu escravo Messenião para procurar o seu irmão gémeo (vv.226-238). Mas se no Curculio, no Epidicus e nos Menaechmi, as viagens por mar não têm, por si só, grande influência no desenrolar da acção, o mesmo já não se passa no Stichus e no Miles gloriosus. Na primeira, o mar, enquanto via de comunicação, assume uma importância primordial no desenrolar da história; de facto, os dois irmãos (Epignomo e Panfilipo), casados com duas irmãs (Panégiris e Pânfila), partiram de Atenas para a Ásia, por onde andaram durante anos, com o objectivo de fazer fortuna e, desse modo, tirar as esposas de uma vida de pobreza. Apesar da pressão exercida pelo pai, que procurava convencê-las de que os maridos teriam refeito as suas vidas e que, por isso, também elas deveriam voltar a casar, as duas irmãs, como Penélope ${ }^{(9)}$, figura que evocam no início da peça, resistiram às pressões do pai e mantiveram-se fiéis aos maridos que, passados três anos, regressaram, depois de terem conseguido fazer fortuna. E, como disse o velho Antifão, foi precisamente o mar que os transportou até elas (v.530). Foi Pinácio, o escravo de Panégiris, quem, no porto, soube da notícia do regresso do seu amo. Desta vez, por via marítima, chegou uma boa nova, que o

\footnotetext{
(9) Assim se considera Panégiris, por ela e a sua irmã Pânfila terem ficado sozinhas e privadas dos maridos durante muitos anos, estando preocupadas, dia e noite, com o que lhes estaria a acontecer (vv.1-6). Sobre os variados tratamentos dados ao mito de Penélope, veja-se F. Oliveira (coord.), Penélope e Ulisses, Coimbra, 2003.
} 
escravo ilustra com as seguintes palavras: "Trago do porto uma nova tão grande, uma alegria tão grande, que a minha própria ama, a não ser que o soubesse, dificilmente se atreveria a pedir aos deuses."(10) (vv.295-296). Por isso, como bom seruus currens, Pinácio veio a correr do porto para dar à sua ama a boa notícia (vv.338-340).

No Miles gloriosus, é por mar que, em primeiro lugar, o soldado Pirgopolinices traz Filocomásio para Éfeso, depois de a ter raptado em Atenas (vv.109-113); de seguida, é o escravo Palestrião que, ao ter conhecimento daquele rapto, se fez ao mar, a fim de ir a Naupacto contar o sucedido ao seu jovem patrão Plêusicles, o primeiro amante de Filocomásio; por fim, é também por via marítima que o jovem apaixonado Plêusicles e a cortesã Filocomásio, juntamente com o seu escravo Palestrião, partem de Éfeso para voltarem a Atenas, depois de terem enganado Pirgopolinices, o soldado fanfarrão (vv.1300 sqq.).

As movimentações por mar não são, naturalmente, representadas em cena, mas sim narradas em diálogos, em monólogos, e, sobretudo, nos prólogos. ${ }^{(11)}$ No Trinummus, é através de um monólogo (vv.820-840) que o velho Cármides, regressado de Selêucia, narra os habituais riscos das viagens por mar que ele, por sorte e com a indispensável protecção de Neptuno, conseguiu superar. A superação desses riscos era agradecida ao deus dos mares por meio de um ritual de manifestação de gratidão, ritual que o velho Teoprópides, na Mostellaria, também profere ao chegar da sua viagem ao Egipto (cf. vv. 431-442). Ainda no Trinummus, verdadeiramente cómico é o relatório da falsa viagem por mar feita pelo Sicofanta a Cármides na cena II do acto IV, onde procura, como já referimos, fazer-se passar por um forasteiro que tinha de entregar, da parte de Cármides, uma importância em dinheiro e duas cartas ao filho Lesbonico e ao amigo Cálicles. Com o que ele não contava era que o

\footnotetext{
(10) Vv.295-296: Tantum a portu adporto bonum, tam gaudium grande affero: uix ipsa domina boc, nisi sciat, exoptare ab dis audeat.

(11) Cf. C. Questa - R. Raffaelli, op. cit., pp.124-125.
} 
velho a quem se dirigiu fosse o próprio Cármides, entretanto regressado do estrangeiro por mar sem que ninguém ainda o soubesse. Por ironia do destino, o Sicofanta acaba, sem o saber, por contar a sua patranha acerca de Cármides ao próprio Cármides, que opta por entrar no jogo, estimulando o Sicofanta a contar a sua viagem mirabolante por locais onde nunca pusera os pés, como Selêucia, Macedónia, Ásia e Arábia (vv. 843-846 e 928-940).

$\mathrm{Na}$ Cistellaria, o prólogo retardado, recitado na cena III do acto I pelo deus Auxílio, faz referência às duas viagens por mar que um mercador fez da ilha de Lemnos a Sícion, viagens de primordial importância, enquanto ponto de partida, para o desenrolar da história que vai decorrer em Sícion e que terminará com a habitual cena de reconhecimento e o feliz casamento de Selénio, a filha reencontrada, com o jovem Alcesimarco.

No prólogo dos Menaechmi fala-se de uma viagem de Siracusa a Tarento, na qual o Mercador Siracusano perdeu um dos filhos (vv.26-36), e foi por mar que um dos irmãos gémeos, o que vivia em Siracusa, chegou a Epidamno (69-71) e percorreu o mar Adriático em busca do irmão (vv.234-238). É curioso verificar que, nesta peça, o escravo Messenião apresenta o porto como um lugar frequentado pelas cortesãs em busca de clientes estrangeiros que elas procuram "seduzir e mandar de volta para casa sem um único cêntimo" (vv.338-343).

No Poenulus, o enredo apresentado no prólogo permite-nos, desde logo, concluir que o mar assume, nesta história, uma importância fundamental, enquanto zona de passagem e espaço narrativo. De facto, foi após uma longa viagem por mar que Adelfásio e Anterástilis, filhas de Hanão, raptadas, ainda crianças, em Cartago por piratas, foram vendidas como escravas ao alcoviteiro Lico (83-90; 897). Foi também por mar que o velho Hanão chegou a Cálidon, onde reencontrou as filhas raptadas (v.114).

No Mercator, o prólogo, proferido pelo jovem Carino, é rico em referências a viagens e em informações acerca da actividade comercial do velho Demifão e do próprio Carino. No entanto, o motivo do comércio, importante no prólogo, acaba por se tornar completamente secundário ao longo da peça. 
Mas é também num navio que Carino, o filho de Demifão, regressa de Rodes, depois de muito tempo de ausência, trazendo consigo uma belíssima escrava - Pasicompsa - por quem se apaixonara e que deixara no porto a bordo do navio (vv.109-110). E é nesse mesmo navio atracado no porto que o velho Demifão vê pela primeira vez Pasicompsa, apaixonando-se perdidamente, de tal modo que, a partir desse momento, não pensa em mais nada senão em tê-la em seus braços (vv.247 sqq.). É, pois, por mar que chega aquela que será o elemento fulcral da história desta comédia. Ainda no Mercator, o mar e as sequelas das náuseas provocadas pelas viagens por mar servem de tema de conversa a Demifão e ao seu filho Carino, para não terem de abordar o assunto que os atormenta a ambos: a paixão por Pasicompsa (vv.366-390).

Nas comédias plautinas, o mar é também a via de comunicação privilegiada para as viagens de negócios de todo o tipo: o comércio propriamente dito, mas também o negócio levado a cabo pelo leno.

Ao primeiro grupo - o dos que viajam por mar na qualidade de mercadores - pertencem o Mercador de Lemnos da Cistellaria, que vai de Lemnos a Sícion; o velho Teoprópides da Mostellaria, que regressa do Egipto; o velho Cármides do Trinummus, que foi à Síria; e o pai dos Menecmos, que se deslocou de Siracusa a Tarento para tratar de negócios. Foi também no mar que o jovem Diábolo da Asinaria conseguiu a sua fortuna, que rapidamente esbanjou em casa da alcoviteira Cleéreta, mãe da cortesã Filénio (v.135).

Ao segundo grupo pertencem o alcoviteiro Lábrax da Rudens, que, seguindo o conselho do velho siracusano Cármides, se dirige à Sicília por mar, vindo de Cirene, cidade do norte de África; os alcoviteiros Lico, do Poenulus, e Dórdalo, do Persa, (vv.576-577), e ainda o Onzeneiro do Epidicus. Todos têm em comum o terem feito uma viagem por mar antes de chegarem à cidade onde se localiza a acção: Cálidon no Poenulus, Atenas no Persa e no Epidicus.

Entre os riscos e os imprevistos que as viagens por mar podiam trazer àqueles que tinham de o enfrentar, o de se deparar com uma tempestade e 
naufragar era o mais frequente, ${ }^{(12)}$ mas, curiosamente, nas comédias plautinas isso verifica-se apenas na Rudens e na Vidularia. O estado muitíssimo fragmentário com que a Vidularia chegou aos nossos dias apenas nos permite indicar, e não mais do que isso, dois passos em que se alude ao naufrágio: o frag. I e o v.72. Já no que diz respeito à Rudens, sabemos que é a estrela Arcturo a responsável, ao provocar uma violenta tempestade, pelo naufrágio do barco do alcoviteiro Lábrax. Ao tomar esta atitude, Arcturo procurou impedir que o alcoviteiro, cujo barco se encontrava no alto mar, conseguisse levar a jovem Palestra para a Sicília, para longe do seu amado Plesidipo. É a própria estrela Arcturo quem, no prólogo, informa os espectadores do desencadear da tempestade, dizendo: "Eu, ao ver que levavam a moça, vim para a ajudar e, ao mesmo tempo, para dar cabo do alcoviteiro. Fiz surgir a tempestade e levantei as ondas do mar." ${ }^{(13)}$ (vv.67-69).

Este naufrágio, referido por várias personagens ao longo da peça: o velho Démones (v.152), Palestra (v.199), Ampelisca (vv.354 e 366-368), o velho Cármides (v.505), e o alcoviteiro Lábrax (vv.801-802, 1308-1309 e 1339), é descrito, como já reconheceram Cesare Questa e Renato Raffaelli, ${ }^{(14)}$ com hábil técnica. É através de um diálogo entre o escravo Ceparnião e o seu patrão Démones, que assistem da praia, que é pormenorizadamente descrita a luta que as jovens Palestra e Ampelisca travavam com as ondas, conseguindo com muito esforço atingir a terra, extenuadas e assustadas (vv.159-184). A tempestade provocada pela estrela Arcturo e o consequente naufrágio revelam-se providenciais para o desenrolar da história, já que é este acontecimento que, por um lado, impede que Palestra seja levada para a Sicília e afastada do seu amado, e, por outro, faz com que a jovem dê à costa junto ao templo de Vénus, precisamente no local onde Plesidipo tinha marcado encontro com o

\footnotetext{
${ }^{(12)}$ Cf. ibidem, pp.135-136.

${ }^{(13)}$ Vv.67-69: Ego quoniam uideo uirginem asportarier, tetuli ei auxilium et lenoni exitium simul: increpui hibernum et fluctus moui maritimos.

(14) Ibidem, p.135.
} 
alcoviteiro para lhe pagar o que faltava para a compra da moça. Mais ainda, é também graças ao naufrágio que Palestra se encontra com o velho Démones e 202 descobre que, afinal, ele é seu pai.

Se analisarmos toda a acção da Rudens, um belíssimo exemplo de comédia de reconhecimento, tendo em conta não só os factos acontecidos em cena, mas também os não menos essenciais acontecimentos previamente narrados no prólogo pela estrela Arcturo, apercebemo-nos de que, apesar do desespero que transparece das palavras proferidas, na sequência do naufrágio, por Palestra (vv.185-219) e Ampelisca (vv.220-229), esse naufrágio desempenhou um papel fundamental para o desenrolar da história e para o seu final feliz. ${ }^{(15)}$ De facto, é o mar que, com as suas marés, traz para junto da casa de Démones todos os elementos primordiais para o desenrolar da acção: as duas náufragas, o alcoviteiro e o baú com os objectos de reconhecimento (vv.907 sqq.). Ainda que num plano meramente secundário, o mar, enquanto propriedade colectiva (vv.977 e 981), aparece também na Rudens, como fonte de alimentos dos pescadores (cf. vv.290-300).

Associados ao mar, aparecem ainda, na comédia plautina, os piratas e os raptos, tema a que já aludimos brevemente a propósito do Poenulus.

Em Plauto, o rapto e o cativeiro acarretam sempre uma mudança de lugar que, a maior parte das vezes explicitamente, outras vezes apenas implicitamente, é concretizada por mar ${ }^{(16)}$ : o jovem Filopólemo, em os Captiui, vai ser encontrado para lá do Golfo de Corinto, na Élide; a jovem Teléstis, no Epidicus, é trazida de Tebas para Atenas por Estratípocles, que a comprou.

No que diz directamente respeito aos piratas, podemos afirmar, com Cesare Questa e Renato Raffaelli ${ }^{(17)}$, que os mares plautinos não parecem estar infestados de piratas, como os de outros textos antigos. A única verdadeira abordagem deste tema é feita pelo escravo Palestrião no prólogo retardado do

\footnotetext{
(15) Cf. ibidem, p.136.

(16) Cf. ibidem, p.133

(17) Ibidem.
} 
Miles gloriosus (cena I do acto II), onde, nos versos 117-122, informa que, na sua viagem de Atenas para Naupacto, cidade da Etólia situada na entrada do Golfo de Corinto, o barco em que seguia foi tomado pelos piratas, e ele próprio capturado. Mas este é o único caso, em Plauto, onde um rapto é descrito como tendo acontecido através de uma abordagem de piratas em alto mar. ${ }^{(18)}$

Nos restantes casos, a viagem por mar é posterior a um rapto acontecido em terra: é o que acontece no Poenulus com Adelfásio e Anterástilis, que foram raptadas nos subúrbios de Cartago e mais tarde trazidas por mar para Anactório, um porto da Acarnânia, perto de Cálidon (vv. 85-88 e 114-115). Nas Bacchides (vv.286-298), o escravo Crísalo faz alusão, mas não mais do que isso, a uma emboscada que a embarcação em que seguia sofreu por parte de um barco pertencente a piratas que queriam roubar-lhes o ouro.

Os vários exemplos apresentados e sucintamente analisados ao longo desta comunicação parecem-nos ser suficientemente elucidativos da importância do mar na comédia plautina, não só como via de comunicação privilegiada para as habituais viagens de negócios de todo o tipo ${ }^{(19)}$, mas também enquanto lugar de acontecimentos imprevistos ${ }^{(20)}$, e ainda, sobretudo, enquanto principal via de comunicação que tem no porto o local de partida e de chegada de personagens responsáveis pelas mudanças de condições que vão afectar o desenrolar da acção ou mesmo solucionar a história. ${ }^{(21)} \mathrm{O}$ mar revela-se, pois, como um espaço verdadeiramente importante e necessário ao funcionamento dos mecanismos narrativos de muitas das comédias plautinas. ${ }^{(22)}$

\footnotetext{
${ }^{(18)}$ Cf. C. Questa - R. Raffaelli, op. cit., p.127.

(19) Cf. Asinaria, Cistellaria, Epidicus, Menaechmi, Mostellaria, Persa, Poenulus, Rudens e Trinummus.

(20) É o caso do naufrágio na Rudens, fundamental para o desenrolar da história e para o seu final feliz.

(21) Cf. Amphitruo, Bacchides, Captiui, Menaechmi, Mercator, Miles gloriosus, Mostellaria, Stichus e Trinummus.

${ }^{(22)}$ Cf. C. Questa - R. Raffaelli, op. cit., pp.134-135.
} 